\section{Rede de Sustentação do PACTO: Acompanhando Percursos e Agenciamentos no Território da Cultura}

\author{
PACTO's Support Network: Following Pathways and \\ Assemblages within the Cultural Territory
}

\section{RESUMO}

O Programa Composições Artísticas e Terapia Ocupacional (PACTO), vinculado ao Departamento de Fisioterapia, Fonoaudiologia e Terapia Ocupacional da Faculdade de Medicina da USP, atua na interface entre os campos das artes e da promoção da saúde, com referências básicas nos movimentos contemporâneos das artes, da reabilitação psicossocial e de produção de subjetividade, em articulação com políticas públicas de saúde, cultura e educação. As ações da Rede de Sustentação desenvolvidas no PACTO priorizam o dispositivo do Acompanhamento Terapêutico no processo de sustentação da participação sociocultural de pessoas em vulnerabilidade. A partir do levantamento de desejos e necessidades dos usuários, os estudantes de Terapia Ocupacional acompanham os deslocamentos das pessoas atendidas, agenciando esses percursos às redes socioculturais da cidade. A metodologia de formação do programa compreende: a orientação das experiências práticas dos estudantes no acompanhamento dos usuários e no mapeamento dos equipamentos de saúde e cultura; o registro das intervenções; sua discussão em supervisões e sua articulação com estudos teóricos em grupos de leitura e escrita. Este artigo apresenta alguns dos resultados dessa experiência integrada de extensão, pesquisa e formação, com foco nos acontecimentos vividos pelos bolsistas do programa Aprender com Cultura e Extensão nos anos de 2011 e 2012. As atividades realizadas ao longo do projeto possibilitaram a construção de discussões pertinentes ao campo, valiosas para a formação profissional e o fortalecimento da Terapia Ocupacional em sua relação com o Acompanhamento Terapêutico.

Palavras-chave: Acompanhamento Terapêutico. Terapia Ocupacional. Interface Artes e Saúde.

\section{Bárbara Harum I \\ Watanabe, Carolina Feng Uei Hun, Erika \\ Alvarez Inforsato e Elizabeth Maria Freire de Araújo Lima \\ Universidade de São Paulo. Faculdade de Medicina, São Paulo, Brasil}




\section{ABSTRACT}

The Artistic Compositions and Occupational Therapy Program (PACTO), under the Department of Physiotherapy, Communication Science \& Disorders, and Occupational Therapy - Faculty of Medicine, USP -, operates at the interface between the fields of arts and health, with basic references in contemporary arts, psychosocial rehabilitation and production of subjectivity, in conjunction with public policies of health, culture and education. The PACTO's Support Network prioritizes in its modus operandi the Therapeutic Accompaniment device in the process of giving support for the sociocultural participation of people in vulnerable conditions. Based on the search of desires and needs of the participants, students of Occupational Therapy accompany the movements of people assisted, linking these pathways to urban socio-cultural networks. The methodology of the training program includes: the guidance on the practical experience of students; the records of interventions, their discussion in supervision spaces; and, its articulation to theoretical studies in reading and writing groups. This article presents some of the results of this integrated experience of university extension, research and training, focusing on the events experienced by the scholarship holders of the Learning with Culture and Extension Program in the years 2011 and 2012. The activities carried out throughout the project allowed the construction of relevant discussions, valuable for training, and strengthening of Occupational Therapy in its relation to the Therapeutic Accompaniment.

Keywords: Therapeutic Accompaniment. Occupational Therapy. Arts and Health Interface.

\section{INTRODUÇÃO}

O Programa Composições Artísticas e Terapia Ocupacional (PACTO), do Laboratório de Estudos e Pesquisa Arte, Corpo e Terapia Ocupacional, há 15 anos vem desenvolvendo ações articuladas de ensino, pesquisa e extensão universitária junto a populações em situação de vulnerabilidade em função de deficiências, sofrimento mental e desvantagem socioeconômica [7].

Vinculado ao Departamento de Fisioterapia, Fonoaudiologia e Terapia Ocupacional da Faculdade de Medicina da USP, o programa atua na interface entre os campos da arte e da promoção da saúde, com referências básicas nos movimentos contemporâneos das artes, da reabilitação psicossocial e de produção de subjetividade em articulação com políticas de atenção às populações em vulnerabilidade social. O PACTO promove espaços coletivos com propostas de artes plásticas e trabalhos corporais, cuja metodologia compreende o fazer artístico, a ampliação da convivência e das trocas sociais, a atualização cultural e a divulgação das produções realizadas em exposições e mostras de arte. As ações do programa visam favorecer a participação dos usuários em atividades culturais e implementar transformações em seus cotidianos. Acentuar o investimento na solução desses entraves colabora com o avanço das pesquisas e práticas voltadas a essas populações, desenvolvidas pelos 
cursos de Terapia Ocupacional nas universidades e nos setores públicos de gestão da saúde e da cultura do país.

Uma das propostas de intervenção do PACTO é a Rede de Sustentação*, criada em 2002 devido ao grande número de usuários que apresentavam dificuldades para a participação e permanência nos projetos coletivos no campo artístico-cultural, em função de dificuldades e impedimentos nas atividades de seu cotidiano, tais como pegar ônibus, preencher formulários, fazer operações com dinheiro, transitar pela rua, deslocar-se pelos espaços físicos e relacionar-se com outras pessoas. As estratégias da Rede de Sustentação priorizam o dispositivo do Acompanhamento Terapêutico (AT), com seus elementos-base - setting aberto, ou seja, espaço variável de circunscrição da relação terapêutica, não restrito à sala do consultório/ambulatório ou ao estabelecimento institucional -, disponibilidade em ato, enquadre flexível e manejo do inusitado - como estratégia de cuidado e agenciamento da participação sociocultural das pessoas atendidas pelo programa (jovens com deficiência intelectual, crianças com dificuldades escolares, idosos com sequelas de acidente vascular encefálico, adultos com traços autísticos, dentre outros). Este dispositivo visa oferecer suporte para que essas pessoas possam integrar ambientes de arte e cultura, um desafio a ser enfrentado por elas, por seus familiares, pelos profissionais de saúde e de cultura e pelos coordenadores de projetos nesse campo. Os casos selecionados para atendimento de AT são aqueles que apresentam necessidade de atenção intensiva e de maior mediação nas relações com seus grupos de pertencimento e com outros espaços socioculturais.

Este trabalho na Rede de Sustentação é desenvolvido por terapeutas ocupacionais e por estudantes do curso de Terapia Ocupacional (TO), e tem apoio da Pró-Reitoria de Cultura e Extensão Universitária (PRCEU-USP) através de bolsas a projetos apresentados ao programa Aprender com Cultura e Extensão desde o ano de 2009. Esses projetos se dirigem ao aperfeiçoamento da formação dos estudantes que deles participam e à ampliação de oportunidades de atendimento para os usuários do PACTO.

Os estudantes, em geral, têm nesta bolsa a primeira oportunidade de realizar um acompanhamento individual durante a graduação em Terapia Ocupacional. $\mathrm{O}$ foco da atuação dos bolsistas está voltado para o agenciamento das redes socioculturais a partir do acolhimento e levantamento de demandas para a condução de seu cotidiano. Essas ações implicam em deslocamentos acompanhados no território da cidade de São Paulo e na exploração de seus recursos, envolvendo o mapeamento de equipamentos de saúde, educação, assistência social, cultura e artes e no contato com as equipes desses serviços. Os bolsistas também realizam a listagem e descrição das principais ações desenvolvidas no âmbito da Rede de Sustentação do PACTO e seus efeitos relevantes, e colaboram com grupos que atuam na interface das artes e da saúde conveniados com o PACTO.

*A Rede de Sustentação é uma das ações desenvolvidas pelo Programa Composições Artísticas e Terapia Ocupacional estudadas na pesquisa Agenciamento Cultural e Cuidado às Populações em Situação de Vulnerabilidade Social: construção e avaliação de tecnologias socioculturais no campo da Terapia Ocupacional, aprovada no Comitê de Ética em Pesquisa da FM-USP (Protocolo de Pesquisa n 043/13). 


\section{MATERIAIS E MÉTODO}

As experiências e intervenções dos bolsistas são registradas em cadernos de campo e acolhidas em discussões do projeto didático-assistencial na perspectiva da TO, que envolve a promoção de saúde como produção de vida, a promoção da participação sociocultural e os processos de criação em oficinas e ateliês de atividades artísticas. Os bolsistas participam da organização e distribuição das atividades do laboratório e discutem as intervenções realizadas em supervisão com os responsáveis pelo projeto. Além disso, articulam essas discussões a perspectivas teóricas em grupos de leitura e escrita e ao projeto mais amplo do laboratório em reuniões de equipe e seminários de aprofundamento temático.

(...) os fios que no princípio nos conduzem para a construção e formação teórica no PACTO passa inegavelmente por lugares da ética, da construção dos direitos e das políticas em saúde que direcionam ou podem orientar este encontro, numa costura capaz de reforçar as passagens entre autonomia pessoal e vínculo social (...) [3].

As ações que constituem a metodologia de formação do Laboratório de Estudos e Pesquisa Arte, Corpo e Terapia Ocupacional [3] e dão sustentação às intervenções no campo da extensão universitária têm como eixos principais:

1. a orientação e registro das intervenções em cadernos de campo - dispositivo de memória e reflexão dos acontecimentos vividos, constituindo material que subsidiará as informações em prontuário e a comunicação com o restante da equipe;

2. o planejamento e discussão das intervenções em supervisões grupais e individuais - encontros semanais que oferecem aos bolsistas, através de uma escuta organizada, o acolhimento em relação aos afetos que emergem do processo de construção vincular, implicado na atuação do AT, e a continência para que essas experiências possam ser pensadas e problematizadas, fomentando a compreensão dos próprios gestos e sua articulação à prática profissional em TO;

3. a reflexão e o estudo teórico em grupo de leitura e escrita - encontros mensais para articulação das discussões das supervisões a perspectivas conceituais em momentos que colocam os estudantes em contato com os referenciais teóricos que sustentam a prática do AT em sua articulação com o campo da TO. O objetivo é possibilitar a compreensão e a problematização das ações desenvolvidas, oferecendo um repertório teórico para que os bolsistas possam estabelecer relações com as suas anotações em cadernos de campo e encontrar, assim, formas de expressão para a própria experiência, inserindo-se num diálogo com outros profissionais do campo. Os textos e referenciais teóricos trabalhados aqui se inserem no solo conceitual que sustenta o trabalho de ensino e pesquisa do laboratório, construído e articulado ao longo dos últimos 20 anos, pautado pelo encontro entre práticas clínicas e sociais, e orientado pela relação com as pessoas atendidas; 
4. as discussões em reuniões de equipe - encontros quinzenais de toda a equipe do PACTO (docentes, terapeutas ocupacionais, estagiários de graduação, estudantes de pós-graduação, profissionais artistas, terapeutas ocupacionais colaboradores e bolsistas) para articulação do conjunto de ações de formação ao projeto mais amplo do laboratório em reuniões clínicas e de gestão em que são abordados temas relacionados aos projetos coletivos e à Rede de Sustentação, bem como seminários de aprofundamento temático apresentado pelos estudantes. A participação neste espaço permite aos bolsistas contextualizar sua ação no contexto coletivo da proposta do PACTO e da estrutura institucional da Universidade, o que possibilita compreender sua atuação no âmbito da extensão universitária.

\section{RELATO DE EXPERIÊNCIA, ALGUNS RESULTADOS}

Nos anos de 2011 e 2012 desenvolvemos o projeto Cartografias do Acompanhamento Terapêutico em Terapia Ocupacional realizado pelo Programa Composições Artísticas e Terapia Ocupacional (PACTO) no agenciamento de redes à população atendida. Durante o ano de 2011 o grupo do PACTO Ateliê Experimental passou por um processo de finalização de suas atividades. $\mathrm{O}$ grupo era formado por jovens e adultos que chegaram ao PACTO com condições variadas, envolvendo limitações nas atividades do cotidiano e na participação social, com poucas oportunidades e muito tempo da semana dedicado a casa e à TV, com relações familiares restritas. O grupo se reuniu durante cerca de cinco anos em torno de experimentações artísticas, corporais e gastronômicas que potencializaram a convivência entre os participantes. No período da finalização desse processo, as bolsistas foram solicitadas a acompanharem os encontros grupais, oferecer suporte à equipe técnica, com ações de aproximação e relação com os usuários, discussões de caso e organização das atividades a serem realizadas. Considerando a importância para os integrantes do grupo de participarem de espaços de encontro e desenvolvimento sociocultural, a equipe desdobrou ações de mapeamento dos equipamentos, projetos de saúde e cultura disponíveis na cidade e agenciou o encaminhamento de participantes para outros espaços de convivência, cuidado e/ou de atividades artístico-culturais. Os bolsistas participaram ativamente dessas ações e realizaram ATs de alguns participantes que não tinham condições de se agenciarem para encontrar novos locais de atendimento e convivência e nem de realizar sozinhos a vinculação a esses locais.

A seguir serão apresentados dois relatos desses ATs, realizados com Ritsuko** e Rafael $^{* * *}$ - casos que foram acompanhados no projeto -, a partir de recortes e problematizações que surgiram no percurso desses atendimentos. Desta forma buscamos evidenciar os resultados obtidos pelo projeto seja no âmbito da formação, preparando os bolsistas para a atuação profissional, seja no âmbito da extensão, contribuindo para promoção de saúde e para a ampliação da participação social das pessoas atendidas.

\footnotetext{
${ }^{* \star} \mathrm{e}^{* * *}$ Nomes fictícios.
} 


\section{ACOMPANHAMENTO TERAPÊUTICO COM RITSUKO: ENCONTRO DE MUNDOS}

Ritsuko chegou ao PACTO em 2003 por uma demanda familiar que consistia na busca de um espaço onde ela pudesse frequentar, realizar atividades e se relacionar com outras pessoas além da família. Na ocasião, ela tinha aproximadamente 60 anos, morava em apartamento próprio junto com o marido e tinha três filhos já crescidos.

Em casa, Ritsuko cuidava de algumas atividades domésticas que eram atravessadas pelos costumes japoneses e ensinamentos de sua mãe. Fazia acompanhamento psiquiátrico há algum tempo em função de sintomas de retraimento e desorganização para a realização de atividades que antes eram parte de sua rotina, ficando bastante prostrada, imóvel e calada. Durante o período de atendimento no PACTO, participou de grupos e foi acompanhada individualmente em vários momentos dessa trajetória. Nos últimos anos, problemas relacionados à circulação sanguínea na região das pernas fizeram com que tivesse que permanecer em repouso por alguns meses e trouxeram limitações em relação à deambulação, gerando uma relação de dependência em grande parte de suas atividades cotidianas, como preparar a alimentação, tomar banho, vestir-se. Com isso, também seus silêncios se tornaram mais presentes. Por um lado, Ritsuko desejava retornar a fazer as atividades do dia a dia, mas por outro passou a delegar a um outro (em geral, o marido) a responsabilidade das mesmas, colocando-se no lugar de alguém que se sente pouco capaz de assumir suas ações e decisões. $\mathrm{O}$ marido também se confundia em questões semelhantes: queria que Ritsuko voltasse a ser mais ativa, mas também tinha um zelo excessivo pela mesma. Ritsuko gostava muito de contar sobre seus filhos e de como os havia criado; adorava, especialmente, as visitas que fazia aos netos. Apesar disso, as visitas aos filhos e aos netos eram pouco frequentes e só aconteciam com muito esforço por parte do marido ou de interferências da equipe do PACTO.

Com a finalização do grupo Ateliê Experimental, do qual participava, agenciou-se a entrada de uma nova acompanhante terapêutica para ajudá-la na procura e vinculação a outro espaço de acolhimento. Desse modo, o primeiro atendimento de Ritsuko aconteceu em seu apartamento no final de 2011.

Para os bolsistas, este costuma ser um momento difícil e desafiador, povoado de muitas perguntas e inquietações, quando se está prestes a entrar em um universo desconhecido que, ao mesmo tempo que assusta, impulsiona a seguir em frente. Como seria o encontro? Como e sobre o que conversariam? O que fariam juntas?

No primeiro dia deste AT, a bolsista foi à casa de Ritsuko, que se apresentou falando muito sobre sua família. Primeiro, seus irmãos: disse que tinha quatro, mas que um deles havia falecido recentemente. Ritsuko nunca chamava seus irmãos pelos nomes, sempre referindo-se a cada um como "irmão mais velho" ou "irmã mais nova", por uma questão de respeito, como ela mesma esclareceu tempos depois. Nestas situações ficam evidentes as influências de elementos étnicos, culturais e da história de vida. Há muitos costumes que se presentificam na forma de Ritsuko ser e agir, assim como muitos costumes e hábitos na forma de ser do acompanhante.

$\mathrm{O}$ encontro entre um terapeuta e um paciente pode significar a possibilidade de 
fusão de dois mundos, de encontro entre simbologias e ancestralidades diferentes. Desenvolver um projeto terapêutico com alguém é propor-se a entrar em seu mundo, andar por ele e nele mergulhar. É tentar desvendar seus mistérios e enigmas, encontrar com ele palavras e modos de agir que possam ressoar significativamente. Nesse sentido,

o analista precisará recorrer às articulações discursivas e imagéticas ${ }^{* * * *}$ específicas do sujeito em questão, pois não é possível o uso de um referente fora da organização semântica do sujeito, se o objetivo é realizar um trabalho que vise a evolução do self do paciente. $\mathrm{O}$ analista poderá vislumbrar, a partir daí, as concepções a respeito da vida, do estar no mundo, das características etno-culturais que fundamentam a subjetividade de seu paciente e de seu vir-a-ser na relação com o outro [8].

Há uma possibilidade de que nesse voo ao mundo do acompanhado, este se sinta motivado a igualmente passear pelo mundo do terapeuta e, assim, ambos criam novos mundos juntos.

No acompanhamento com Ritsuko, a bolsista tentava encontrar essas articulações discursivas e imagéticas; entendia intuitivamente e através das supervisões que, para acessar o mundo de Ritsuko, era preciso utilizar o que ressoava em sua sensibilidade. Alguns códigos foram descobertos ao longo dos encontros. O primeiro a ser identificado foi o amor que Ritsuko demonstrava sentir em relação à língua japonesa. Em certos momentos, ela misturava em sua fala palavras em japonês. Ela também verbalizava bastante sobre como era importante para si saber esse idioma. Por uma sorte dos encontros, a bolsista que acompanhava Ritsuko entendia um pouco da língua, compreendeu algumas palavras e construiu seu relacionamento com ela através de um idioma que a tocava especialmente. Assim, pôde perceber que utilizar a mesma palavra em japonês ou em português causava um efeito diferente em Ritsuko. Portanto, tentar falar algumas palavras em japonês foi uma forma de estabelecer um vínculo. Por outro lado, é preciso tomar certo cuidado, pois cada um significa aquilo que está ao redor de maneiras diferentes, cada um tem seus símbolos. Ter um conhecimento de uma outra língua pode ser um recurso a mais no acompanhamento, desde que se seja capaz de apreender aquilo que o interlocutor quer dizer ao ouvinte através de sua própria linguagem.

Safra [8] afirma que o conceito de ideograma ajuda a pensar como se estrutura o idioma do self. O ideograma é uma representação pictórica que, a partir dos elementos do mundo, torna-se a representação de uma palavra, de um significado. Desse modo,

a fala do indivíduo nestas condições nomeia suas experiências no tempo e no espaço, ao mesmo tempo em que, por seu caráter ideogramático, apresenta em historicidade o estilo pelo qual ele se situa no tempo e no espaço do mundo. É uma fala que revela seu percurso pela vida e sua origem étnica, com seus encontros e desencontros: é a apresentação de seu estilo de ser [8].

****De acordo com Safra, "as formas imagéticas organizam-se nos diferentes campos sensoriais: imagens sonoras, imagens visuais, imagens gustativas, imagens tácteis" [8]. 
O acolhimento da linguagem própria de Ritsuko possibilitou uma ampliação de seu espaço comunicativo, bem como uma aceitação de seu modo de fazer.

Essa dimensão de delicadeza, frequente em encontros de AT, tornou-se preponderante no percurso de trabalho com Ritsuko, que se desdobrou em entrevistas de equipamentos de saúde e cultura da região de sua residência, e em encaminhamentos para uma instituição especializada em atendimento a idosos, com atividades corporais em grupo.

E em relação ao vínculo constituído no acompanhamento, uma pequena cena do encerramento desse trabalho mostra como neste caso os dois sujeitos envolvidos puderam conhecer o mundo e os hábitos um do outro, olha-se atentamente e se relacionar a partir do que emergia no ambiente do encontro.

Depois de conversarmos bastante sobre o tempo que passamos juntas, percebi que minha permanência de duas horas já tinha se esgotado a um tempo atrás. Era hora de ir embora. Havia algo em mim que desejava postergar esse momento de despedida, mas não tinha como. Minha bolsa estava se encerrando e Ritsuko já havia se vinculado a um outro serviço. Então, eu lhe disse que já estava indo. Abraçamos-nos bem forte, dizendo uma a outra que sentiríamos saudades. Enquanto arrumava minhas coisas, Ritsuko perguntou se eu não iria ao banheiro. Fiquei com uma cara de incógnita e perguntei: “Ué, por que você acha que eu quero ir ao banheiro?”. Ela me responde: “Você sempre vai ao banheiro antes de ir embora...” [4].

\section{TECENDO RELAÇÕES E ANDANÇAS JUNTO A RAFAEL}

Rafael iniciou sua trajetória no PACTO em março de 2002, aos vinte e quatro anos. Residia com a mãe, pai e irmãos. As atividades que compunham seu cotidiano em geral se limitavam a assistir televisão, dormir bastante, observar a movimentação das pessoas na rua e acompanhar a mãe em seus afazeres domésticos e de gerenciamento de uma pequena venda de doces na entrada de sua casa.

A mãe relata que aos sete anos frequentou uma escola normal e, devido às dificuldades de aprendizado, foi encaminhado para uma instituição tradicional, especializada no atendimento de pessoas com deficiência intelectual, onde realizou oficinas e permaneceu sendo assistido até os dezenove anos.

O ingresso de Rafael no PACTO veio acompanhado de seu interesse em participar de oficinas de pintura e desenho. Ao longo dos anos, transitou por alguns grupos do programa, tais como o PACTO Oficinas e o Ateliê Experimental. Paralelamente à participação nos grupos, ele foi acompanhado por outros bolsistas do projeto durante oito semestres. Essas experiências resultaram em sua vinculação com um grupo de futebol do Centro de Práticas Esportivas (CEPEUSP) e em uma oficina de arte no Centro de Convivência e Cooperativa (CECCO) do Pq. Previdência.

Os primeiros contatos da bolsista com Rafael se estabeleceram a partir das vivências no grupo Ateliê Experimental, no qual desenvolvia atividades artísticas e corporais. Com a perspectiva de finalização do grupo, um AT foi construído para retomar a participação de Rafael na Oficina de Arte do CECCO.

As primeiras experimentações do AT ocorreram no final de algumas sessões do 
grupo, quando a bolsista o acompanhava até o ponto de ônibus a fim de oferecer suporte a sua entrada no coletivo correto para o retorno a sua casa, já que ele não era alfabetizado. Durante esses momentos conversavam sobre suas impressões e participações no grupo, os trabalhos desenvolvidos e as atividades de interesse comum. Aos poucos construíram uma relação em um enquadre aberto, onde os acontecimentos ocorridos no espaço coletivo concorriam para a construção e estabelecimento da relação acompanhante-acompanhado.

Rafael não sabia ler, entretanto sabia qual ônibus o levaria para casa. Sua conduta na escolha dos ônibus surpreendeu a bolsista que, aos poucos, pôde compartilhar dos códigos e linguagens singulares utilizados por ele para compor esta ação.

Todo o caminho para o CECCO foi guiado por Rafael, desde as orientações dos pontos, as solicitações de paradas e as descrições dos caminhos. Perguntei-me como ele fazia isso se não sabia ler? Experimentei a primeira das muitas desconstruções que ainda vivenciaria acerca de uma pessoa com deficiência, um outro constituído de experiências, vivências e marcas, iguais a mim. Era vivo e latente o fato de que os códigos que utilizamos para nos relacionarmos com a vida extrapolavam uma catalogação ou premeditação, eles existiam de diferentes maneiras [9].

Durante o caminho Rafael permanecia calado, prestando muita atenção ao deslocamento dos ônibus, e aos poucos foi possível compreender que essa postura se referia a um sentimento de responsabilidade assumida por seu posto de guia do trajeto, já que a bolsista desconhecia o caminho.

Winnicott denominou holding (ou sustentação)

a tudo que, no ambiente, fornecerá a uma pessoa a experiência de uma continuidade, de uma constância tanto física quanto psíquica, que exercida continuamente possibilitará uma integração interna facilitadora da compreensão dos acontecimentos vividos [2].

Dessa maneira, ao entender a dinâmica utilizada por Rafael para ir ao CECCO, a bolsista buscou estar atenta a todos os fatores que pudessem colocá-lo em uma situação de imprevisibilidade, fornecendo assim alternativa e subsídios para que respostas fossem construídas.

Partindo dos interesses de Rafael em circular por lugares novos da cidade e da necessidade de readequação de horários da bolsista, uma nova proposta se instaurou, possibilitando a inserção de novos mecanismos, fatores, espaços e discussões para a relação. Novas inquietações e percepções foram formuladas, a "renovação de gestos, ações e sentidos" foi desencadeada, constituindo assim um novo lugar de reflexão e formulação de teorias e pensamentos acerca dessas experiências singulares [2].

Andar por espaços culturais provocou a necessidade de pesquisa de exposições pela cidade de São Paulo, de caminhos a serem percorridos, de meios de transporte que deveriam utilizar e posteriormente deu lugar à realização de um registros e roteiro, por meio de desenhos, acerca das novas experiências.

A imprevisibilidade das novas situações e a circulação por diferentes lugares exigiram manejos e contribuições de ambas as partes, resultando em um fortalecimento do 
vínculo e na construção de um espaço potencial onde os desejos, angústias e dúvidas encontravam espaços para serem expressos, questionados e muitas vezes solucionados.

As vivências proporcionadas pelos ATs resultaram em uma maior circulação e apropriação dos espaços, no fortalecimento dos vínculos com o CECCO e com as oficinas e na ativação de inúmeras áreas do viver, dando condições a Rafael de despertar para o cultivo dessas novas aquisições e, consequentemente, para novas formas de inscrições de sua subjetividade.

\section{CONSIDERAÇÕES FINAIS}

As vivências proporcionadas pelo projeto forneceram subsídios e disparadores para a composição e reflexão acerca da formação em TO e sua potencialização por meio do dispositivo do AT. Os manejos instaurados ao longo dos trabalhos impulsionaram a construção de importantes formas de pensar a clínica dentro dessa inusitada dinâmica.

As supervisões realizadas ao longo do processo com a docente e a terapeuta ocupacional responsáveis pelo projeto, juntamente com o estudo de textos relacionados ao AT e às relações vinculares entre terapeuta e paciente, possibilitaram às bolsistas a construção de reflexões e discussões pertinentes ao campo, de grande valia para a formação profissional nesta área e para o fortalecimento da TO na relação com o AT. As estudantes foram, assim, instrumentalizadas para lidar com questões relacionadas a: acessibilidade às redes socioculturais; construção de redes de pertencimento social; coordenação e desenvolvimento de grupos e ao próprio atendimento clínico de sujeitos em situação de vulnerabilidade.

Em meio ao acompanhamento das atividades cotidianas dos usuários, uma nova forma de aproximação e de entendimento se confeccionou. $\mathrm{O}$ acolhimento dos gestos criadores, das necessidades, dos desejos e do respeito em relação à temporalidade de cada um possibilitou uma vinculação potente e de qualidade, resultando em experiências significativas para todos os atores envolvidos.

Um ponto de complicação relevante apareceu durante o mapeamento de dispositivos de saúde, com a frequente recusa dos serviços para o atendimento dos que precisavam, o que, aliado às questões econômicas e familiares, dificultou a efetivação de outras possibilidades de participação para estes usuários. $\mathrm{O}$ trabalho realizado pode, por outro lado, levar a processos de composição com recursos do próprio território. Nesta perspectiva, a direção privilegiada pelo projeto não é a de incluir alguém numa configuração social hegemônica, mas sim de reinventar o próprio território da cidade e reabilitá-lo [1] em suas dimensões geográficas, política e cultural; dimensões que comportam ainda um plano micropolítico, aquele dos encontros e afetos que se constelam na relação com a atendente da lanchonete, com o motorista do ônibus, com o segurança de um museu, etc. Enfim, todo um conjunto de ações que provocam, instigam, convidam aos elementos constitutivos de um território e seus equipamentos de saúde e cultura a construirem coletivamente novas formas de convivência com a diferença [6].

O projeto hoje se abre para novas perspectivas, no sentido de avançar em sua implementação, com a realização de um rastreamento das ações concluídas, construindo 
um material de avaliação e consulta para o laboratório, que deverá ser divulgado em ambientes da TO como referência para outros estudantes e profissionais, inciativa que compreende a confecção deste artigo.

Os desenvolvimentos futuros prevêem que os novos bolsistas se voltem ainda mais para colaborar na sustentação de projetos grupais na interface arte-saúde, com a pesquisa de formas de fomento à participação sociocultural de pessoas em vulnerabilidade social, buscando agenciar as demandas das pessoas atendidas nos planos artístico-cultural e clínico. Para a articulação desses planos o projeto deverá intensificar sua abordagem da hibridização entre arte, saúde e cultura. Pretende-se, ainda, criar um espaço para o aprofundamento em questões técnicas e teóricas deste campo, incluindo o estudo de políticas culturais para pessoas em vulnerabilidade e a compreensão e atuação no campo dos projetos culturais e da efetivação dos direitos.

Se a terapia ocupacional pode ser um dos lugares privilegiados do olhar para o fazer, talvez pudesse o ser do ponto de vista dos agenciamentos (...) É isto agenciar: estar no meio, sobre a linha de encontro de um mundo interior e de um mundo exterior (...) [5].

\section{REFERÊNCIAS}

[1] CASTRO, E. D. Atividades artísticas e Terapia Ocupacional: construção de linguagens e inclusão social. 2001. 326fls. Tese (Doutorado em Ciências da Comunicação). Escola de Comunicação e Artes da Universidade de São Paulo, São Paulo, 2001.

[2] CASTRO, E. D. Inscrições da relação terapeuta-paciente no campo da terapia ocupacional. Rev. Ter. Ocup. Univ. São Paulo, v. 16, n. 1, p. 14-21, jan./abr., 2005.

[3] CASTRO, E. D.; INFORSATO, E. A.; ANGELI, A. A. C.; LIMA. E. M. F. A. Formação em Terapia Ocupacional na Interface das Artes e da Saúde: a experiência do PACTO. Rev. Ter. Ocup. Univ. São Paulo, Brasil, v. 2o, n. 3, p. 149156, dez., 2009.

[4] HUN, C. F. Diário de Campo. Arquivos do PACTO, Laboratório de Estudos e Pesquisa Arte e Corpo e Terapia Ocupacional. Centro de Docência e Pesquisa em TO da USP. São Paulo, 2011/2012.

[5] INFORSATO, E. A. Clínica Barroca: exercícios de simpatia e feitiçaria. 2005. 169 fls. Dissertação (Mestrado). Pontifícia Universidade Católica de São Paulo, São Paulo, 2005.

[6] LIMA, E. M. A.; YASUI, S. Territórios e Sentidos: espaço, cultura e cuidado na atenção em saúde mental. 2013. (Inédito)

[7] LIMA, E. M. A.; INFORSATO, E. A.; LIMA, L. J. C. de; CASTRO, E. D. Ação e criação na interface das artes e da saúde. Rev. Ter. Ocup. Univ. São Paulo, v. 20, n. 3, p. 143-148, set./dez., 2009.

[8] SAFRA, G. A face estética do self: teoria e clínica. São Paulo: Unimarco Editora, 2005 .

[9] WATANABE, B. H. Diário de Campo. Arquivos do PACTO, Laboratório de 
Estudos e Pesquisa Arte e Corpo e Terapia Ocupacional. Centro de Docência e Pesquisa em TO da USP. São Paulo, 2011/2012.

[10] WATANABE, B. H.; HUN, C. F. U.; INFORSATO, E. A.; LIMA, E. M. F. A. Cartografias do Acompanhamento Terapêutico em Terapia Ocupacional no agenciamento de redes à população atendida. In: II Simpósio de Acompanhamento Terapêutico e Saúde Pública, São Bernardo do Campo, 2012.

BÁRBARA HARUMI WATANABE graduanda do curso de Terapia Ocupacional da Faculdade de Medicina da Universidade de São Paulo (FM-USP) e bolsista do projeto entre 2011 e 2013

CAROLINA FENG UEI HUN terapeuta ocupacional da Faculdade de Medicina da Universidade de São Paulo (FM-USP) e bolsista do projeto nos anos de 2011 e 2012

ERIKA ALVAREZ INFORSATO terapeuta ocupacional do Departamento de Fisioterapia, Fonoaudiologia e Terapia Ocupacional da Faculdade de Medicina da Universidade de São Paulo (FM-USP) e responsável pelo projeto

ELIZABETH MARIA FREIRE DE ARAúJo LIMA docente do Departamento de Fisioterapia, Fonoaudiologia e Terapia Ocupacional da Faculdade de Medicina da Universidade de São Paulo (FM-USP) e responsável pelo projeto - e-mail: beth.lima@usp.br 